\title{
Correction to: Can your advertising really buy earned impressions? The effect of brand advertising on word of mouth
}

\author{
Mitchell J. Lovett ${ }^{1}$ (D) $\cdot$ Renana Peres ${ }^{2} \cdot$ Linli $\mathrm{Xu}^{3}$ \\ Published online: 9 January 2020 \\ (C) Springer Science+Business Media, LLC, part of Springer Nature 2020
}

\section{Correction to: Quantitative Marketing and Economics (2019) 17:215-255 https://doi.org/10.1007/s11129-019-09211-9}

The table below should replace Table 1. The related text in section 3.3 needs also be corrected and should read:

Table 1 presents category specific information about the advertising, media mentions, and WOM mentions data. This table communicates the large variation across categories in the use of the different types of advertising and in the number of media mentions. Looking across all brands, the highest spender on TV ads is AT\&T, the highest spender on Internet display ads is TD AmeriTrade, and the brand with the highest number of news mentions is Facebook. The average number of total mentions for a brand in the sample is 15.8 (equivalent to 36 million mentions in the population), the brand with the highest total WOM is Coca Cola, and the brand with the highest online WOM is Facebook. In Web Appendix 1, we present time series plots for four representative brands as well as descriptive statistics and correlations for the data.

The online version of the original article can be found at https://doi.org/10.1007/s11129-019-09211-9

Mitchell J. Lovett

mitch.lovett@simon.rochester.edu

Renana Peres

peresren@huji.ac.il

Linli Xu

linlixu@umn.edu

1 Simon Business School, University of Rochester, Rochester, NY, USA

2 School of Business Administration, Hebrew University of Jerusalem, 91905 Jerusalem, Israel

3 Carlson School of Management, University of Minnesota, Minneapolis, MN, USA 


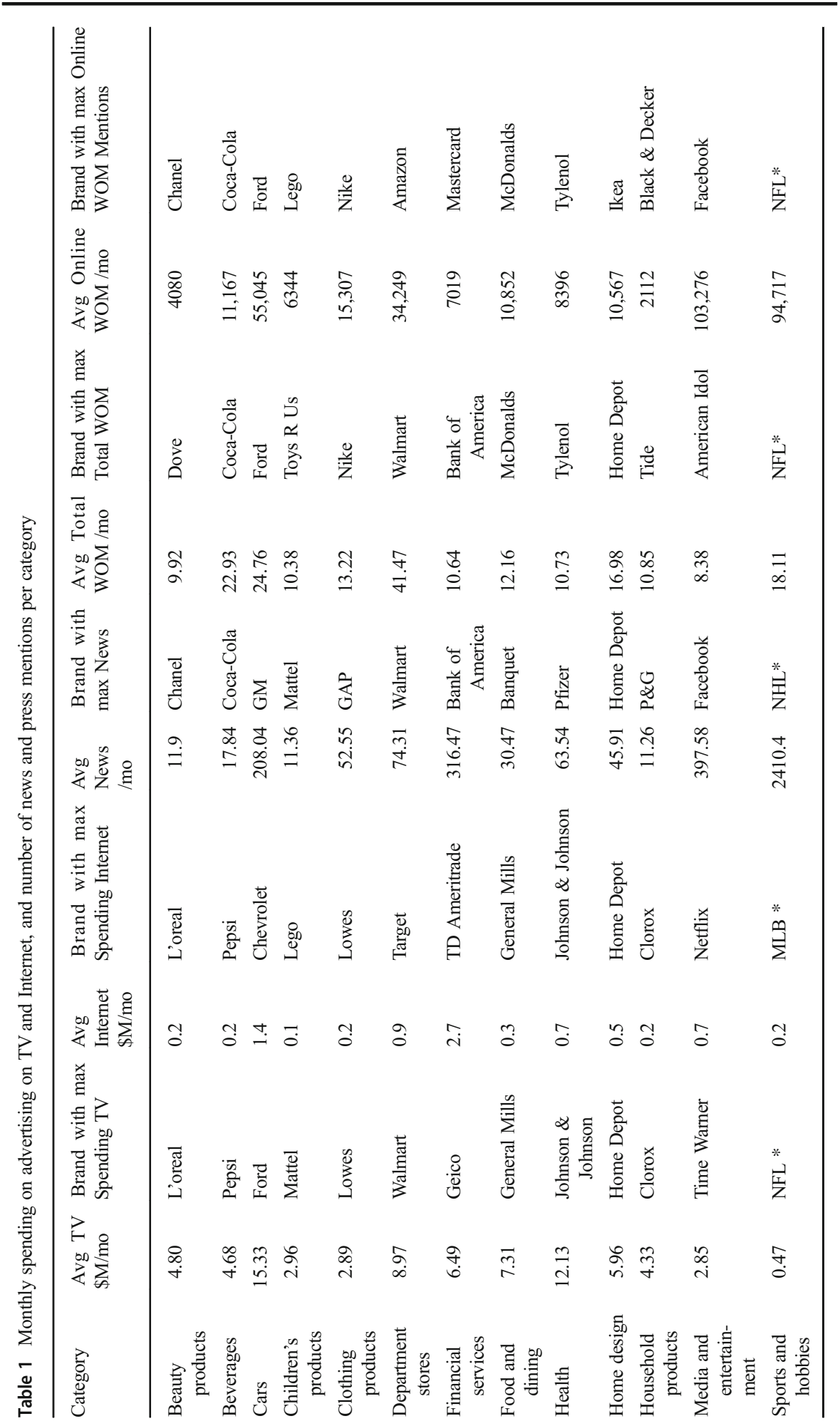




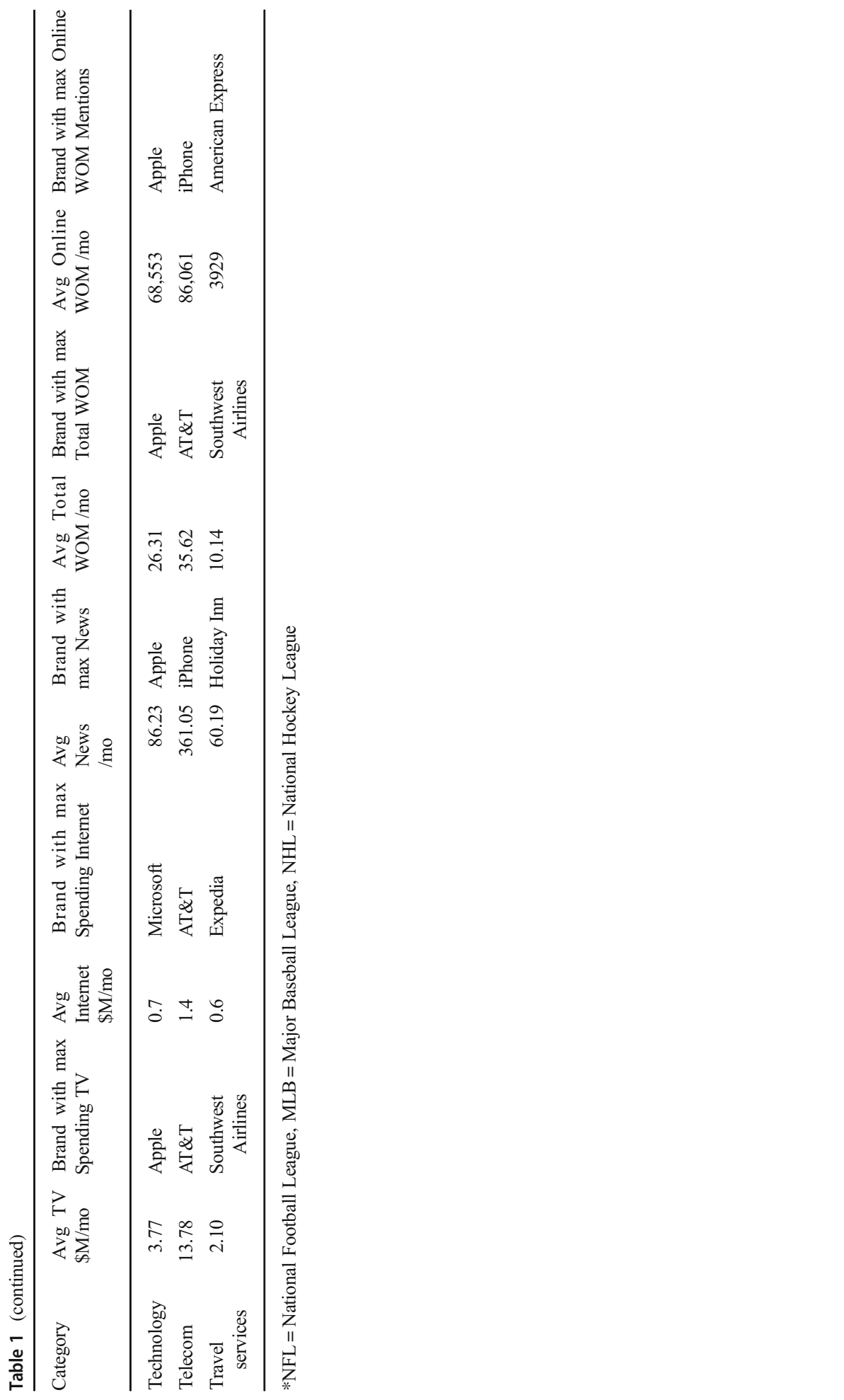

